\title{
Distributed hydrologic modeling of a sparsely monitored basin in Sardinia, Italy, through hydrometeorological downscaling
}

\author{
G. Mascaro ${ }^{1,2,3}$, M. Piras ${ }^{2,3}$, R. Deidda ${ }^{2,3}$, and E. R. Vivoni ${ }^{1,4}$ \\ ${ }^{1}$ School of Sustainable Engineering and the Built Environment, Arizona State University, Tempe, AZ, USA \\ ${ }^{2}$ Dipartimento di Ingegneria Civile, Ambientale ed Architettura, Università degli Studi di Cagliari, Cagliari, Italy \\ ${ }^{3}$ Consorzio Interuniversitario Nazionale per la Fisica delle Atmosfere e delle Idrosfere, Tolentino, Italy \\ ${ }^{4}$ School of Earth and Space Exploration, Arizona State University, Tempe, AZ, USA
}

Correspondence to: G. Mascaro (gmascaro@asu.edu)

Received: 27 May 2013 - Published in Hydrol. Earth Syst. Sci. Discuss.: 18 June 2013

Revised: 8 September 2013 - Accepted: 24 September 2013 - Published: 24 October 2013

\begin{abstract}
The water resources and hydrologic extremes in Mediterranean basins are heavily influenced by climate variability. Modeling these watersheds is difficult due to the complex nature of the hydrologic response as well as the sparseness of hydrometeorological observations. In this work, we present a strategy to calibrate a distributed hydrologic model, known as TIN-based Real-time Integrated Basin Simulator (tRIBS), in the Rio Mannu basin (RMB), a medium-sized watershed $\left(472.5 \mathrm{~km}^{2}\right)$ located in an agricultural area in Sardinia, Italy. In the RMB, precipitation, streamflow and meteorological data were collected within different historical periods and at diverse temporal resolutions. We designed two statistical tools for downscaling precipitation and potential evapotranspiration data to create the hourly, high-resolution forcing for the hydrologic model from daily records. Despite the presence of several sources of uncertainty in the observations and model parameterization, the use of the disaggregated forcing led to good calibration and validation performances for the tRIBS model, when daily discharge observations were available. The methodology proposed here can be also used to disaggregate outputs of climate models and conduct high-resolution hydrologic simulations with the goal of quantifying the impacts of climate change on water resources and the frequency of hydrologic extremes within medium-sized basins.
\end{abstract}

\section{Introduction}

Mediterranean areas are highly sensitive to climate variability, and this vulnerability has significant impacts on water resources and hydrologic extremes. During the last few decades, intense flood and flash-flood events have caused relevant socioeconomic losses (Chessa et al., 2004; Delrieu et al., 2005; Silvestro et al., 2012), while persistent drought periods have limited water availability, causing restrictions that mainly affected the agricultural sector, often a pillar of the local economy. Unfortunately, future climate projections (IPCC, 2007; Schörter et al., 2005; Giorgi, 2006) depict an even worse scenario since they predict, with high probability, that Mediterranean countries will suffer a general decreasing water availability (in terms of both rainfall and runoff) and an increasing occurrence of extreme hydrological events (IPCC, 2008; Frei et al., 2006). This may cause, in cascade, a reduction of crop production and, in the worst scenario, a decrease of their quality due to the concomitant degradation of cultivated soils and water used for irrigation (Olesen and Bindi, 2002; Schörter et al., 2005).

As most semiarid areas of the world, Mediterranean watersheds are characterized by a complex hydrologic response due to the erratic and seasonal nature of rainfall, its strong interannual variability, and the highly heterogeneous land surface properties (Moussa et al., 2007). These features lead to the possible occurrence of a large range of initial basin wetness conditions prior to a storm event, and, in turn, to strong non-linear relations between rainfall and runoff (Piñol et al., 1997; Gallart et al., 2002; Beven, 2002). Modeling such 
complex systems in a continuous fashion to manage and plan water resources as well as to predict hydrologic extremes is a difficult task. A possible strategy is the use of physically based hydrologic models that are able to quantify the vertical and lateral water fluxes in spatially distributed fashion at high (sub-daily) time resolution, and to capture the interaction between surface and subsurface processes (VanderKwaak and Loague, 2001; Ivanov et al., 2004a; Camporese et al., 2010, among others). These models are able to (i) reproduce the different basin states during the dry season, the wetting-up period and the wet season (Noto et al., 2008), and (ii) to simulate the diverse surface and subsurface runoff types (Vivoni et al., 2007, 2010) that typically characterize the hydrological regime of Mediterranean basins (Piñol et al., 1997).

Distributed hydrologic models have been applied to study the hydrologic impacts of future climate change scenarios, with forcing provided by general (GCMs) or regional (RCMs) climate models (e.g., Abbaspour et al., 2009; Cayan et al., 2010; Montenegro and Ragab, 2012; Liuzzo et al., 2010; Sulis et al., 2011). In Mediterranean areas, conducting studies based on this approach is challenging for two reasons. First, the basin size is relatively small in most areas $\left(<1000 \mathrm{~km}^{2}\right)$, and a spatiotemporal-scale gap exists between GCM and RCM outputs and the scale of the dominant hydrological processes (Wood et al., 2004). Second, the data required to calibrate distributed hydrologic models are often characterized by limited spatial coverage and coarse time resolution, and they may have not been collected during simultaneous periods. For example, streamflow observations may be available in a period with no meteorological or rainfall data. In the following, we refer to this type of problem as data sparseness.

In this paper, we use a distributed hydrologic model known as the TIN-based Real-time Integrated Basin Simulator (tRIBS) to simulate the response of the Rio Mannu basin (RMB), a watershed of $472.5 \mathrm{~km}^{2}$ located in southern Sardinia, Italy. This basin is one of the study areas of a multi-institutional and interdisciplinary project that aims at analyzing ongoing and future climate-induced changes in hydrological budgets and extremes across the Mediterranean and neighboring regions (Ludwig et al., 2010). The RMB was selected as the study site for a number of reasons. First, it includes within its boundary an agricultural experimental farm where productivity of several crops grown in Sardinia (wheat, artichokes, corn, pasture, and grapes) is continuously monitored by the Sardinian Agency for Research in Agriculture (AGRIS). Second, during the last $30 \mathrm{yr}$, the RMB has been affected by prolonged drought periods that caused water restrictions for the agricultural sector, with significant financial losses and social conflicts as a consequence. As a result, this watershed is a representative study case on the island of Sardinia for conducting a multidisciplinary analysis of the local impacts of climate changes, ranging from the quantification of the future availability of water resources and occurrence of hydrologic extremes, to the evaluation of the corresponding social and economical vulnerability.

As in most Mediterranean basins, the application of process-based hydrologic models like tRIBS in the RMB is prevented by the availability of hydrometeorological observations. In this study, we propose an approach to circumvent this problem based on two statistical downscaling (or disaggregation) tools that allow creating the high-resolution forcing (precipitation and potential evapotranspiration) required to perform detailed hydrologic simulations at hourly time resolution. The downscaling tools are calibrated using data collected at different resolutions over diverse time periods. After demonstrating the reliability of each disaggregation algorithm, we show how these tools can be used to calibrate and validate the hydrologic model adequately based on streamflow observations available over a multi-year period, encompassing a wide range of flood and low flow conditions. The downscaling routines proposed here will be adopted in subsequent work to disaggregate outputs of different RCMs and create the high-resolution inputs (hourly in time, $\sim 10 \mathrm{~km}$ in space) for the tRIBS model, with the goal of quantifying the impacts of a set of future climate scenarios on the water resources of the RMB (Ludwig et al., 2010).

The paper is organized as follows. In Sect. 2, we briefly introduce the tRIBS model, while the study area and the geospatial data set used to set up the hydrologic simulations are described in Sect. 3. In Sect. 4, we first illustrate the challenges associated with the lack and sparseness of the hydrometeorological observations and, next, we describe in detail the two downscaling tools proposed to disaggregate precipitation (in space and time) and potential evapotranspiration (in time). The setup of the tRIBS model and the calibration and validation performances are discussed in Sect. 5, while conclusions are outlined in Sect. 6.

\section{The physically based distributed hydrologic model}

We used the physically based tRIBS model that is able to simulate hydrologic processes continuously in distributed fashion by explicitly accounting for the spatial variability of hydrometeorological forcing and basin properties (Ivanov et al., 2004a, b). The model represents topography via a triangulated irregular network (TIN), thus allowing a significant reduction of the number of computational nodes as compared to grid-based models (Vivoni et al., 2004, 2005). In tRIBS, the TIN is used to discretize the domain into Voronoi polygons, which are the basic computational elements where the equations governing the water and energy balances are solved using a finite-difference control-volume approach. As a result of the local dynamics and the lateral mass exchanges between adjacent polygons, the model can reproduce the distributed hydrologic response of a catchment by simulating a range of hydrological processes: canopy interception and transpiration, evaporation from bare soil and vegetated 

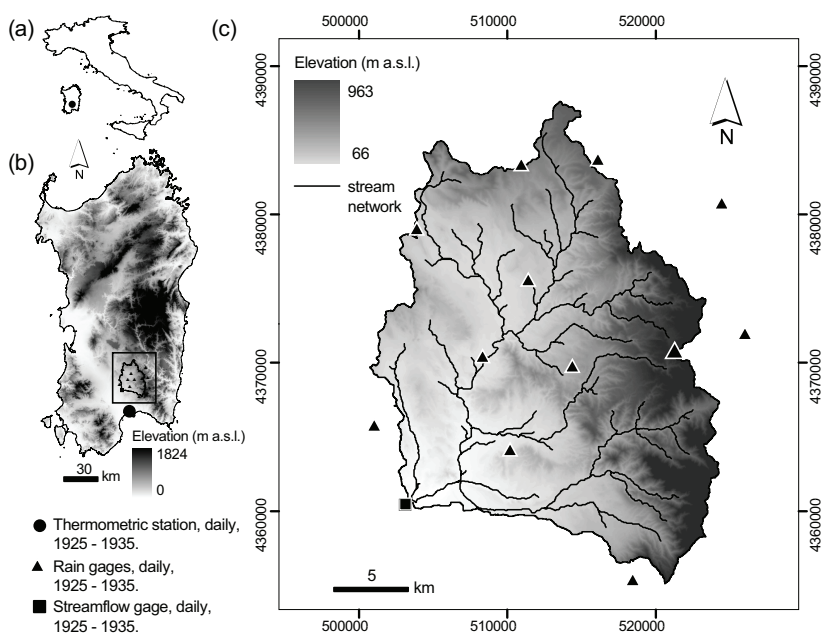

Fig. 1. Location of the Rio Mannu di San Sperate at Monastir basin (RMB) within (a) Italy and (b) the island of Sardinia. (c) Digital elevation model (DEM) of the RMB including UTM coordinates. Panels (b) and (c) also report the position of the thermometric station, rain gages and streamflow gage at the basin outlet with daily data observed during the years 1925-1935.

surfaces, infiltration and soil moisture redistribution, shallow subsurface transport, and overland and channel flows. Model parameters can be grouped into routing, soil and vegetation parameters. The first group is spatially uniform, while the other two sets vary in space and are provided through maps and look-up tables. A detailed description of the physical processes simulated by the model and its parameterization is given by Ivanov et al. (2004a, b).

For the purpose of this study, we briefly illustrate the different precipitation inputs that the model is able to ingest and the methods available to estimate the evapotranspiration losses. Precipitation forcing can be provided as spatially distributed grids, as those produced by weather radars (Ivanov et al., 2004b; Vivoni et al., 2006; Nikolopoulus et al., 2011), numerical weather forecasting models or reanalysis products (Vivoni et al., 2009; Robles-Morua et al., 2012), and stochastic downscaling models (Forman et al., 2008; Mascaro et al., 2010). In addition, tRIBS can be forced by point observations of rain gages that are spatially interpolated through the Thiessen polygon method. Due to the specific characteristics of the physical equations implemented in the model, the precipitation input should have at least hourly resolution to capture the dynamics of the hydrologic response under different types of storm events.

The actual evapotranspiration $\left(\mathrm{ET}_{\mathrm{a}}\right)$ losses are estimated as a fraction of the potential evapotranspiration $\left(\mathrm{ET}_{0}\right)$ based on the soil moisture available in the upper soil layer, using a piecewise-linear equation with different parameterization if applied to bare soils or vegetated surfaces (Mahfouf and Noilhan, 1991; Ivanov et al., 2004a). ET $_{0}$ can be in turn computed by solving the energy balance inside the model through
Table 1. Physiographic characteristics of the RMB including area $\left(A_{b}\right)$, minimum $\left(z_{\min }\right)$, maximum $\left(z_{\max }\right)$ and mean $\left(z_{\text {mean }}\right)$ elevation, mean slope $\left(\beta_{\text {mean }}\right)$, length of the main reach $(L)$, and concentration time $\left(T_{\mathrm{C}}\right)$, computed using the Giandotti formula: $T_{\mathrm{c}}=\frac{4 \sqrt{A_{b}}+1.5 L}{0.8 \sqrt{z_{\text {mean }}-z_{\min }}}$.

\begin{tabular}{ccccccc}
\hline$A_{\mathrm{b}}$ & $z_{\min }$ & $z_{\max }$ & $z_{\text {mean }}$ & $\beta_{\text {mean }}$ & $L$ & $T_{\mathrm{c}}$ \\
\hline$\left(\mathrm{km}^{2}\right)$ & $(\mathrm{m}$ a.s.l. $)$ & $(\mathrm{m}$ a.s.l. $)$ & $(\mathrm{m}$ a.s.l. $)$ & $(\%)$ & $(\mathrm{km})$ & $(\mathrm{h})$ \\
472.5 & 66 & 963 & 296 & 17.3 & 39 & 12 \\
\hline
\end{tabular}

the Penman-Monteith approach (Penman, 1948; Monteith, 1965), based on soil and vegetation parameters in addition to hourly meteorological data provided as time series observed at stations or as grids. Alternatively, the model can be forced by time series or grids of $\mathrm{ET}_{0}$ computed off-line.

Outputs of the tRIBS model include time series of discharge at any location in the stream network, and spatial maps of hydrologic variables (e.g., actual and potential evapotranspiration, soil water content at different depths, ground water table position) at specified times or integrated over the simulation period. Recently, the code has been parallelized for use in high-performance computing platforms (Vivoni et al., 2011), thus increasing the feasibility of long-term simulations of large watersheds, including within an ensemble modeling framework. These characteristics make the tRIBS model suitable to be used in studies aimed at quantifying the impact of climate change on water resources and hydrologic extremes at the watershed scale while addressing the different sources of modeling uncertainty.

\section{Study area and land-surface data set}

The case study is the Rio Mannu di San Sperate at Monastir basin (RMB), a watershed of $472.5 \mathrm{~km}^{2}$ located in southern Sardinia, Italy (Fig. 1). Topography is mostly gently rolling, with an average elevation of $296 \mathrm{~m}$, except for a mountainous zone in the southeastern part with a maximum height of $963 \mathrm{~m}$. The flat downstream areas were originally swampy, and, since the beginning of 20th century, they have been drained through a system of artificial channels and converted into fertile agricultural fields. The main basin physiographic characteristics, including elevation, slope and channel properties, are summarized in Table 1.

The climate of the study region is Mediterranean with extremely dry summers and rainfall from September to May. The average annual precipitation is $680 \mathrm{~mm}$, with $94 \%$ concentrated in the rainy season. Mean monthly temperatures vary between $9{ }^{\circ} \mathrm{C}$ in January and $25^{\circ} \mathrm{C}$ in July and August. The mean annual $\mathrm{ET}_{0}$ in the basin is $750 \mathrm{~mm}$ (Pulina, 1986). Given the topographic characteristics and the geographic position, precipitation in the form of snow occurs rarely and can be neglected in hydrological simulations. The streamflow 
(a)

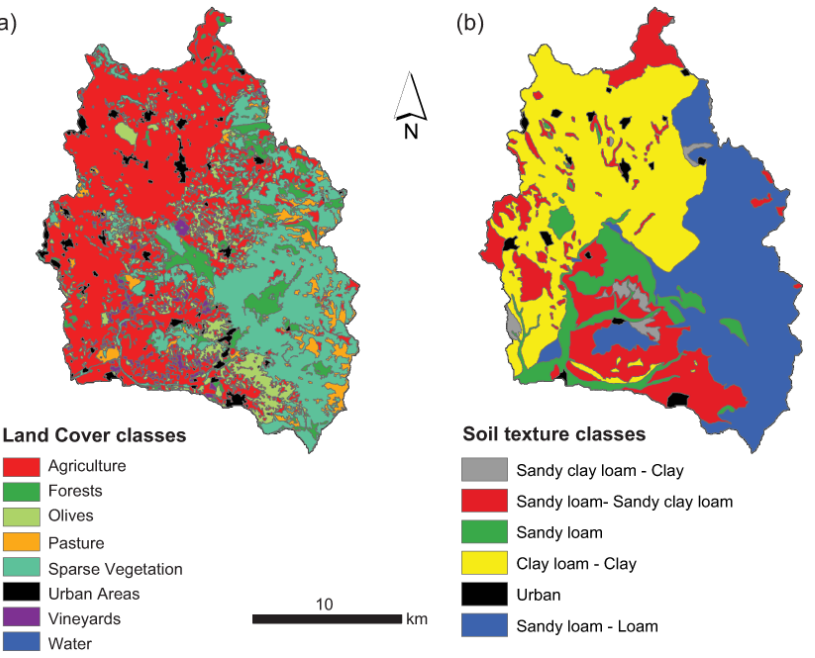

Fig. 2. (a) Land cover and (b) soil texture maps used as input for the tRIBS model.

regime is characterized by a low flow throughout the year (less than $1 \mathrm{~m}^{3} \mathrm{~s}^{-1}$ ), with a few flood events per year mostly caused by frontal systems with typical duration of 1-3 days (Chessa et al., 1999; Mascaro et al., 2013).

The geospatial data for the RMB were provided by different agencies of the Sardinian Region Government and include the following: (i) a digital elevation model (DEM) at $10 \mathrm{~m}$ resolution (Fig. 1c); (ii) the land cover (LC) map in digital format, derived from the COoRdination de l'INformation sur l'Environnement (CORINE) project of the European Environment Agency (EEA) for the year 2008; (iii) a hard copy of a pedological map of Sardinia at scale 1:250000 (Aru et al., 1992); and (iv) orthophotos of the entire island for years 1954 and 2006.

The LC and soil texture maps were pre-processed to be utilized as model inputs. The original CORINE LC classes were aggregated into 8 groups, obtaining the map shown in Fig. 2 a. According to our reclassification, the dominant classes are agriculture $(\sim 48 \%)$ and sparse vegetation $(\sim 26 \%)$, including Mediterranean species. Other categories include olives, forests, pastures, vineyards and urban areas, with minor percentages as summarized in Table 2. Due to the large time discrepancy between the calibration and validation period (years 1930-1932, as described in Sect. 4.1) and the year 2008 when the LC map was released, we evaluated the stationarity of the LC conditions, by carefully comparing the orthophotos of years 1954 and 2006. This analysis based on visual inspection revealed minimal differences in vegetation coverage and a negligible urban expansion, thus providing confidence in the use of the LC map of the year 2008 to carry out the hydrological simulations. In the RMB, irrigation is applied on about $50 \%$ of the agricultural land and is mostly concentrated in summer. As a result, the irrigated wa-
Table 2. Land cover and range of soil texture classes used as input for the tRIBS model, with the corresponding percentage of basin area.

\begin{tabular}{lclc}
\hline $\begin{array}{l}\text { Land } \\
\text { cover class }\end{array}$ & $\begin{array}{c}\text { \% basin } \\
\text { area }\end{array}$ & $\begin{array}{l}\text { Range of soil } \\
\text { texture classes }\end{array}$ & $\begin{array}{c}\% \text { basin } \\
\text { area }\end{array}$ \\
\hline Agriculture & 47.64 & $\begin{array}{l}\text { Sandy clay loam - clay } \\
\text { Forests }\end{array}$ & $\begin{array}{l}\text { Sandy loam - } \\
\text { sandy clay loam }\end{array}$ \\
Olives & 7.09 & 19.59 \\
Pastures & 8.07 & Sandy loam & 8.84 \\
Sparse vegetation & 5.43 & Clay loam - clay & 36.66 \\
Urban areas & 3.08 & Urban & 1.52 \\
Vineyards & 2.44 & Sandy loam - loam & 31.82 \\
Water & 0.02 & & \\
\hline
\end{tabular}

ter mainly affects the low flow regime of the river only during the summer months.

The pedological map was digitized and georeferenced resulting in 17 classes in the RMB. For each class of the map, Aru et al. (1992) provide a range of soil texture and a qualitative description of soil depths. To reduce the uncertainty on the soil texture classification, a series of field campaigns were conducted in 2011 by the project described in Ludwig et al. (2010), during which a total of 50 soil samples of $80 \mathrm{~cm}$ depth were collected throughout the watershed and analyzed to characterize the texture. These data were then used as a guide to aggregate the 17 classes and reduce the range of possible soil texture types for each class. The resulting map is shown in Fig. 2b, while the percentage distribution of the classes is reported in Table 2.

\section{Hydrometeorological data downscaling tools}

Precipitation, meteorological and streamflow data were collected during different (and sometimes non-overlapping) time periods and at different time resolutions. This data sparseness represents a challenge for the calibration and validation of the hydrologic model. The Italian Hydrologic Survey collected and published discharge data at the RMB outlet (square in Fig. 1c) for $11 \mathrm{yr}$ from 1925 to 1935 . During this period, daily rainfall data were observed by 12 gages (triangles in Fig. 1c), while one thermometric station, located in the city of Cagliari near the basin (circle in Fig. 1b), recorded daily minimum $\left(T_{\min }\right)$ and maximum $\left(T_{\max }\right)$ temperature. This data set cannot be directly used for model calibration due to the coarse temporal resolution (daily) and the lack of meteorological data needed to calculate the energy balance and estimate $\mathrm{ET}_{0}$ at hourly scale with the Penman-Monteith formula.

Here, we propose an approach based on two downscaling tools of precipitation and potential evapotranspiration forcing that can be used to create the high-resolution input required to calibrate the hydrologic model with reasonable 
Table 3. Hydrometeorological data used in the study, including the resolution, the number of gages and the source for each type of data and available period. The sources include the following: AI, "Annali Idrologici"; IHS, Italian Hydrologic Survey (data provided by the branch in Sardinia); and ARPAS, the Sardinian Agency for Environmental Protection.

\begin{tabular}{|c|c|c|c|c|c|c|c|c|c|}
\hline \multirow[b]{2}{*}{ Period } & \multicolumn{3}{|c|}{ Streamflow } & \multicolumn{3}{|c|}{ Precipitation } & \multicolumn{3}{|c|}{ Meteorological } \\
\hline & Resolution & \# of gages & Source & Resolution & \# of gages & Source & Resolution & \# of gages & Source \\
\hline 1925-1935 & Daily* & 1 & AI & Daily* & 12 & AI & Daily** & 1 & $\mathrm{AI}$ \\
\hline 1986-1996 & - & - & - & $1 \mathrm{~min}$ & 204 & IHS & - & - & - \\
\hline 1995-2010 & - & - & - & - & - & - & $1 \mathrm{~h}^{* * *}$ & 1 & ARPAS \\
\hline
\end{tabular}

* Read at 9:00 a.m. ** Only minimum and maximum temperature $\left(T_{\min }\right.$ and $\left.T_{\max }\right)$. *** Air temperature, air humidity, global radiation, and wind speed at $2 \mathrm{~m}$ height.
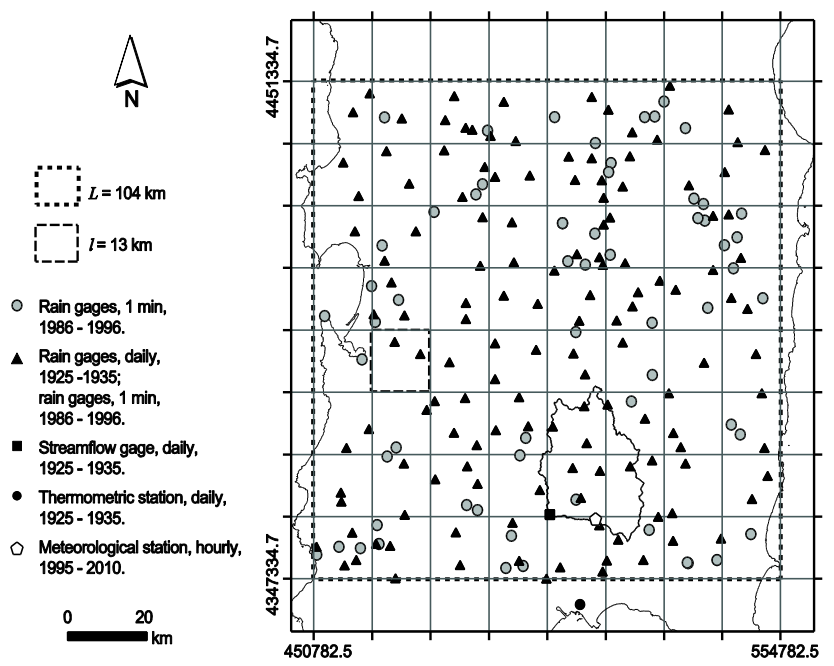

Fig. 3. Location of rain gages, meteorological stations and streamflow gage. The square with a dashed line is the coarse domain $L \times L(L=104 \mathrm{~km})$ containing the fine-scale grid at resolution $l \times l(l=13 \mathrm{~km})$ used to calibrate the precipitation downscaling tool. See Table 3 for details.

accuracy. The downscaling tools are calibrated with highresolution precipitation and meteorological data recorded in the RMB during more recent years: (i) precipitation records at $1 \mathrm{~min}$ from automatic rain gages observed during the years 1986-1996, and (ii) hourly meteorological data from 1 station over the period 1995-2010. The characteristics of the hydrometeorological data, including resolution, availability period, and source are summarized in Table 3, while their locations are reported in Fig. 3.

The high-resolution precipitation data were used to calibrate a multifractal downscaling model that is able to generate hourly precipitation grids from the coarse daily data. The meteorological data were utilized to develop a disaggregation method that is capable of generating a time series of $\mathrm{ET}_{0}$ at hourly scale starting from the daily $T_{\min }$ and $T_{\max }$. Through these tools, we were able to disaggregate the coarse data set observed in the calibration and validation periods selected in the years 1925-1935, producing the forcing at hourly resolution for tRIBS. In the following, we first describe how we se- lected the model calibration and validation periods and then illustrate in detail the two downscaling algorithms.

\subsection{Selection of calibration and validation periods}

The discharge data in the RMB outlet were published in annual technical reports of the Italian Hydrologic Survey (called "Annali Idrologici") for the years 1925-1935. Streamflow was estimated through a rating curve by reading the water stage every day at 9:00 a.m. (Table 3). The information published in each annual report included the time series of daily water stage and discharge; the rating curve, provided as a set of stage and discharge points (linear interpolation is performed between each point); the stage and discharge values that were measured during the year to update the rating curve; and a description of the possible problems encountered during the year that affected the current or the past discharge estimates.

To select the periods for model calibration and validation, we carefully inspected the information and the data contained in the technical reports, finding the following: (i) the rating curves exhibited significant variation across the $11 \mathrm{yr}$; and (ii) a number of significant problems were reported for some years that affected the quality of the discharge estimates (e.g., in 1929, an eddy close to the measurement device caused a consistent bias). To minimize data uncertainty, we identified three consecutive years (1930-1932) during which the published rating curves did not vary significantly and problems were not reported. Next, we fitted a rating curve using the stage and discharge measurements over the three years and used this to derive a discharge time series from the stage records. Due to the larger number of flood events, the year 1930 was selected as a calibration period, while the years 1931 and 1932 were used to validate the model performance.

\subsection{Precipitation downscaling tool}

The precipitation downscaling procedure is based on the multifractal model known as the Space Time RAINfall (STRAIN) model that simulates precipitation variability in temporal, spatial and spatiotemporal frameworks over a wide range of scales, through binary multifractal cascades (Deidda et al., 1999; Deidda, 2000). Rainfall models based on 
Table 4. Parameter values of the calibration relation in Eq. (1) of the STRAIN model for applications in the time and space-time domains, which are valid when expressing $R$ in $\mathrm{mm} \mathrm{h}^{-1}$.

\begin{tabular}{lrrr}
\hline & $c_{\infty}$ & $\mathrm{a}$ & $\gamma$ \\
\hline Time domain & 0.43 & 0.93 & 1.94 \\
Space-time domain & 1.49 & 2.23 & 3.04 \\
\hline
\end{tabular}

the multifractal theory have been extensively used to characterize and simulate the rainfall statistics at different spatial and temporal scales (see, e.g., Schertzer and Lovejoy, 1987; Over and Gupta, 1996; Menabde et al., 1997; Deidda et al., 2004; Veneziano and Langousis, 2005, 2010; Langousis et al., 2009, 2013). Our objective is to downscale daily precipitation observed by a network of gages and produce gridded maps at hourly resolution. For this purpose, we developed a disaggregation tool based on the study of Badas et al. (2006), who applied the STRAIN model in Sardinia in a spatiotemporal framework from the coarse scale $L=104 \mathrm{~km}$ and $T_{1}=6 \mathrm{~h}$ up to a fine scale $l=13 \mathrm{~km}$ and $T_{2}=45 \mathrm{~min}$. Figure 3 shows the coarse domain and the fine-scale grid, along with the location of the rain gages used to calibrate the downscaling model. In this coarse spatial domain, precipitation data are available at $1 \mathrm{~min}$ resolution in the period 1986-1996 and at daily resolution in the years 1930-1932 (Fig. 3 and Table 4).

Our downscaling approach consists of two steps sketched in Fig. 4. We first use STRAIN to perform a temporal disaggregation of the rainfall volume observed in the domain $L \times L(L=104 \mathrm{~km})$ from the daily scale $T_{0}=24 \mathrm{~h}$ to the scale $T_{1}=6 \mathrm{~h}$ (Fig. 4a). Next, we apply the model in a spatiotemporal framework to downscale precipitation from the coarse scale $L \times L \times T_{1}$ to the fine scale $l \times l \times T_{2}(l=$ $13 \mathrm{~km}, T_{2}=45 \mathrm{~min}$ ), as in Badas et al. (2006) (Fig. 4b). The resulting gridded data are then aggregated at hourly resolution to be used as input for the tRIBS model.

The STRAIN model reproduces observed multifractal properties of precipitation fields by means of a log-Poisson stochastic generator dependent on two parameters, $c$ and $\beta$, which are estimated through scale invariance and multifractal analysis between the coarse and the fine scales. Next, empirical calibration relations are identified between estimates of $c$ and $\beta$ over a large set of rainfall events and one or more coarse-scale predictors. The dependence between the parameters of multifractal models and coarse meteorological predictors has been documented in other studies (e.g., Perica and Foufoula-Georgiou, 1996; Gebremichael et al., 2006; Over and Gupta, 1996; and Veneziano et al., 2006). In previous applications (e.g., Deidda et al., 1999, 2004, 2006; Badas et al., 2006), parameter $\beta$ was found to be fairly constant at $e^{-1}$, while $c$ was found to be related to the coarse-scale mean rain-

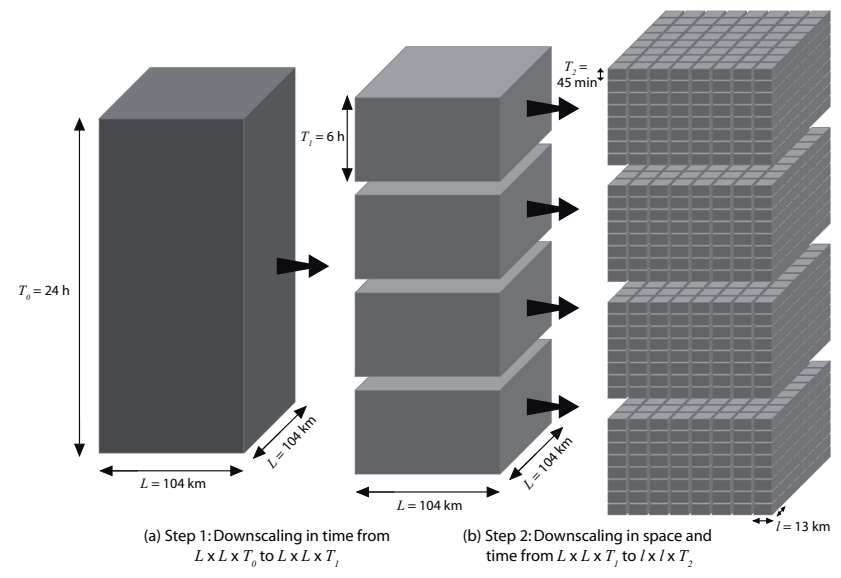

Fig. 4. Schematic of the precipitation downscaling tool based on STRAIN model. The procedure consists of two steps: (a) disaggregation in the time domain from the coarse scale $L \times L \times T_{0}(L=$ $\left.104 \mathrm{~km}, T_{0}=24 \mathrm{~h}\right)$ to the fine scale $L \times L \times T_{1}\left(T_{1}=6 \mathrm{~h}\right)$; and (b) disaggregation in the space-time domain from the coarse scale $L \times L \times T_{1}$ to the fine scale $l \times l \times T_{2}\left(l=13 \mathrm{~km}, T_{2}=45 \mathrm{~min}\right)$.

fall intensity $R\left(\mathrm{~mm} \mathrm{~h}^{-1}\right)$ as

$c=c_{\infty}+a \cdot e^{-\gamma R}$,

with parameters $c_{\infty}, a$ and $\gamma$. The model is operationally applied as follows: (i) the coarse predictors are used to derive values of $c$ and $\beta$ from the calibration relations, and (ii) an ensemble of small-scale rainfall fields is generated, each representing a possible scenario statistically consistent with the same coarse-scale condition. In the following, we briefly describe the model calibration in the time and space-time frameworks and the evaluation of the performances of the downscaling procedure, referring the reader to Deidda (2000) and Deidda et al. $(1999,2004)$ for additional details on the scale invariance and multifractal analysis.

\subsubsection{Step 1: precipitation downscaling in the time domain}

Similarly to Badas et al. (2006), we created a spatial grid with step $l=13 \mathrm{~km}$ and extent $L=104 \mathrm{~km}$, characterized by the presence of at least one gage in each pixel (Fig. 3). The $1 \mathrm{~min}$ rainfall gage data were aggregated at a timescale $T_{2}=45 \mathrm{~min}$. Next, for a given time step, a gridded precipitation field was derived by averaging the data observed by the gages in each $l \times l$ pixel. As a result, we created a data set of gridded precipitation fields at resolution of $13 \mathrm{~km}$ and $45 \mathrm{~min}$ over the coarse domain of $104 \times 104 \mathrm{~km}^{2}$ for the period 1986-1996.

To calibrate the STRAIN model in the time framework, we selected a total of 300 precipitation events at the coarse scale $L \times L \times T_{0}$. For each event, we performed the scale invariance and multifractal analyses from $T_{0}=24 \mathrm{~h}$ to $T_{1}=$ $6 \mathrm{~h}$ and estimated the parameters $c$ and $\beta$. To identify the 

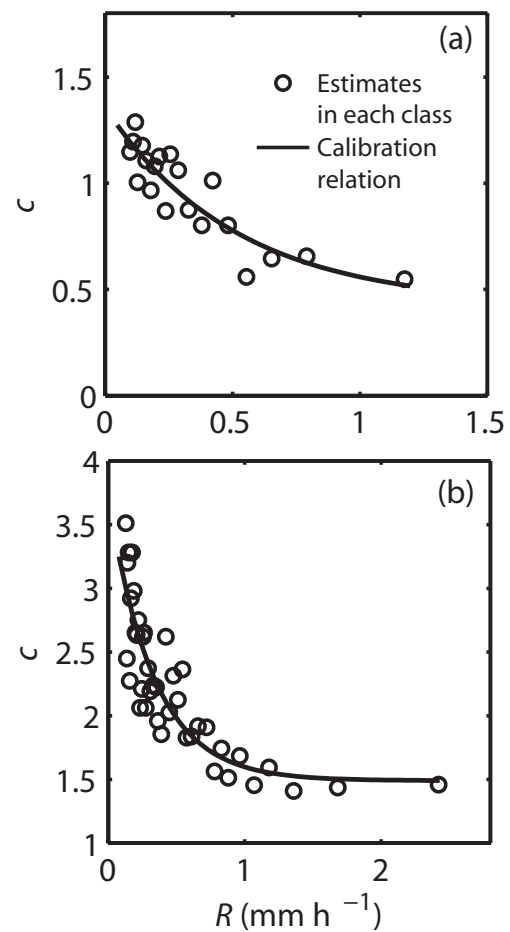

Fig. 5. Calibration relations in Eq. (1) between the STRAIN model parameter $c$ and the coarse-scale mean precipitation intensity $R$ for application in the (a) time and (b) space-time domains.

calibration relation, (i) we sorted the events in order of increasing coarse-scale intensity $R$ and grouped them in 20 classes of 15 events, and (ii) for each class, we averaged the $c, \beta$ and $R$ values. Consistent with previous applications, we found $\beta$ close to $e^{-1}$ and $c$ to be linked with $R$ through Eq. (1). This relation is shown in Fig. 5a along with the $c$ estimates in the 20 classes, while the values of $c_{\infty}, a$ and $\gamma$ are reported in Table 4.

\subsubsection{Step 2: precipitation downscaling in the space-time domain}

The application of STRAIN in the space-time framework is based on the work of Badas et al. (2006). When the model is applied in three dimensions, a velocity parameter $U$ needs to be identified to transfer the statistical properties from space scales to time scales (Deidda et al., 2004). For our data set, we adopted the value $U=17.33 \mathrm{~km} \mathrm{~h}^{-1}$ found by Badas et al. (2006). We estimated $c$ and $\beta$ on a total of 800 precipitation events, by performing the scale invariance and multifractal analysis from the coarse $L \times L \times T_{1}\left(L=104 \mathrm{~km}, T_{1}=\right.$ $6 \mathrm{~h})$ to the fine $l \times l \times T_{2}\left(l=13 \mathrm{~km}, T_{2}=45 \mathrm{~min}\right)$ scales. As in the time domain application, events were grouped in 40 classes of 20 events to estimate the calibration relation. We found $\beta$ close to $\mathrm{e}^{-1}$ across the classes, while Eq. (1) was used to relate $c$ and $R$. The resulting calibration relation is shown in Fig. 5b, and the estimates of $c_{\infty}, a$ and $\gamma$ are re- ported in Table 4. Badas et al. (2006) showed the presence of non-homogeneity in the spatial distribution of precipitation on the island, which can be mainly associated with elevation. Since the STRAIN model reproduces homogeneous fields, we used the procedure described by Badas et al. (2006) to apply the model while accounting for the effect of orography.

\subsubsection{Validation of the precipitation downscaling tool}

The performances of the downscaling tool were first evaluated separately for the time and the space-time disaggregation steps, according to the procedure described below. For each class created to group the coarse-scale rainfall events, we randomly selected 10 of them. For each event, we used STRAIN to generate an ensemble of 100 disaggregated series with $c$ derived from the corresponding calibration relation (Fig. 5 and Table 4). The observed and synthetic highresolution rainfall series of the 10 events were standardized (i.e., divided by corresponding $R$ to have a unitary coarsescale mean) and pooled together. The model ability was then tested by comparing empirical cumulative density functions (ECDFs) of the 10 observed standardized rainfall series at the fine resolution $\left(i^{*}\right)$, against the $90 \%$ confidence intervals derived from the $10 \times 100$ standardized ensemble members. Examples are presented in Fig. 6 for different $R$. Panels (a)-(d) show results for the time domain, revealing the good ability of the STRAIN model to reproduce the statistical variability in time. Panels (e)-(h) illustrate the space-time framework and show that, despite some exceptions (e.g., Fig. 6g), the model is also able to capture the small-scale spatiotemporal precipitation distribution with reasonable accuracy.

As a next step, we validated the entire downscaling procedure by selecting the same daily rainfall events used to verify the application in the time domain. For each event, the STRAIN model was first used to disaggregate in time the mean daily rainfall intensity over the domain $L \times L$, producing an ensemble of 10 disaggregated series at time resolution $T_{1}=6 \mathrm{~h}$ (Fig. 4a). Next, the STRAIN model was applied to disaggregate in space and time each intensity in the domain $L \times L \times T_{1}$, generating an ensemble of 10 fields at the fine scale $l \times l \times T_{2}$ (Fig. 4b). Summarizing, for every precipitation event observed in $24 \mathrm{~h}$ in the spatial domain of $104 \times 104 \mathrm{~km}^{2}$, we created a set of 100 (10 by 10$)$ disaggregated grids at the resolution of $13 \mathrm{~km}$ in space and 45 min in time. The comparison between the ECDFs of the observed standardized rainfall series of 10 events pooled together against the $90 \%$ confidence intervals of the simulated fields is reported in panels (i)-(l) of Fig. 6 for four classes. The figures show that the downscaling tool has a relatively good skill in reproducing the rainfall distribution at fine scales. 

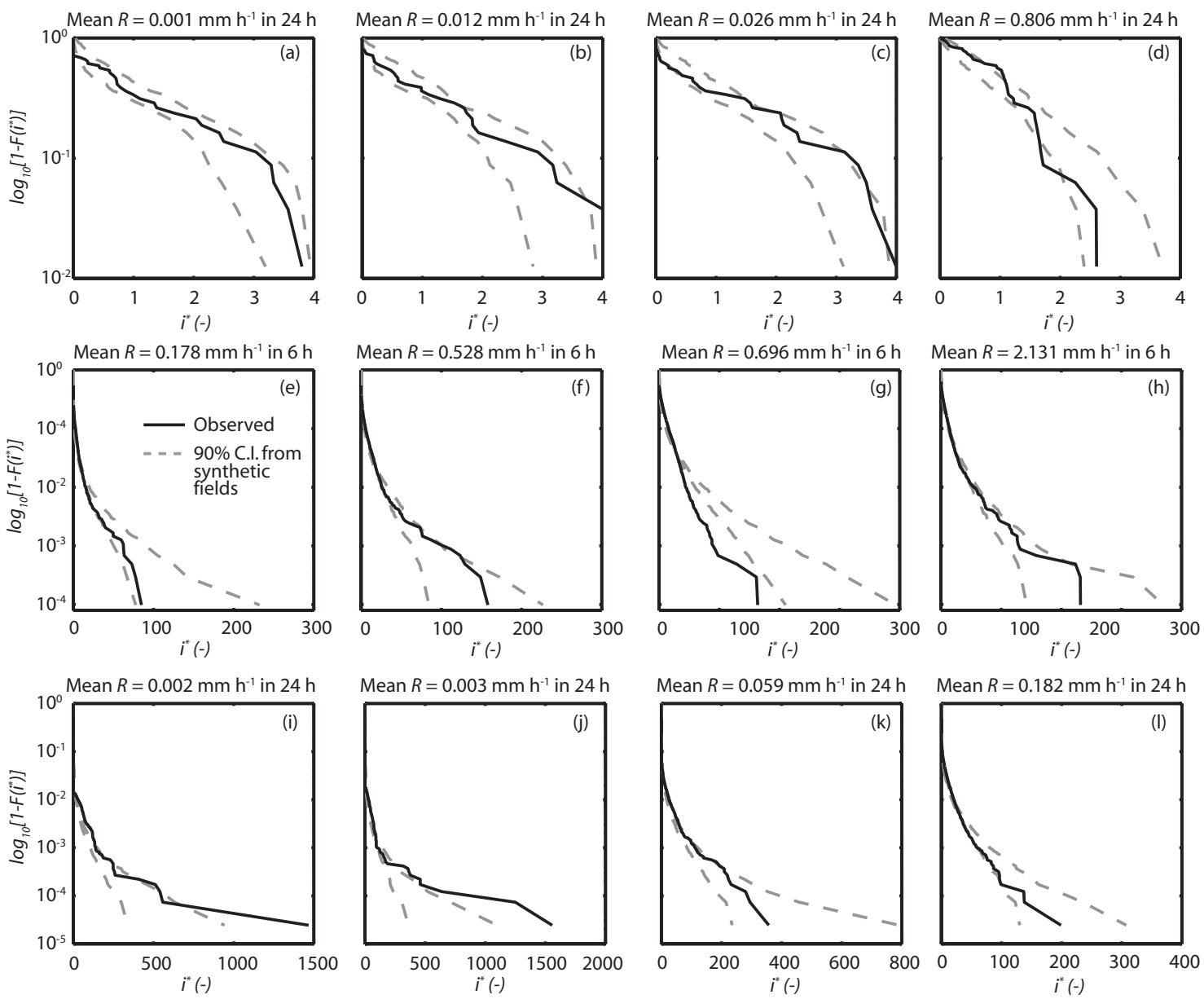

Fig. 6. Comparison between the empirical cumulative density functions (ECDFs) of the small-scale observed precipitation fields and the $90 \%$ confidence intervals derived from an ensemble of 100 synthetic fields generated with the downscaling tool. The small-scale precipitation intensities were standardized and indicated as $i^{*}$ (see text for details). Panels (a)-(d) and (e)-(h) show results for the applications in the time and space-time domains, respectively, while panels (i)-(l) report results for the entire disaggregation procedure.

\subsection{Potential evapotranspiration downscaling tool}

If the hourly meteorological data needed for the internal computation of $\mathrm{ET}_{0}$ with the Penman-Monteith formula are not available, the tRIBS model can be applied by ingesting hourly time series of potential evapotranspiration $\mathrm{ET}_{0}$ computed off-line with some other approach. In our case, during the period 1930-1932, $\mathrm{ET}_{0}$ can be only estimated at daily resolution from $T_{\min }$ and $T_{\max }$ using formulas like the Hargreaves equation (Hargreaves, 1994; Hargreaves and Allen, 2003). To circumvent this scale discrepancy, we designed a procedure to disaggregate $\mathrm{ET}_{0}$ from daily to hourly scale, using, as calibration data set, hourly observations of meteorological variables available from 1995 to 2010 at the station shown in Fig. 3. The method is based on the computation of dimensionless functions $\phi_{m}(h)$ that reproduce, for each month $m=1,2, \ldots, 12$, the average daily cycle of $\mathrm{ET}_{0}$ for hours $h=0,1, \ldots, 23$. These functions are defined as

$\varphi_{m}(h)=\frac{\left\langle\left.\mathrm{ET}_{0}(h, m)\right|_{\mathrm{H}}\right\rangle}{\left\langle\left.\mathrm{ET}_{0}(m)\right|_{\mathrm{D}}\right\rangle}$,

where $\left\langle\left.\mathrm{ET}_{0}(h, m)\right|_{\mathrm{H}}\right\rangle$ and $\left\langle\left.\mathrm{ET}_{0}(m)\right|_{\mathrm{D}}\right\rangle$ are the monthly climatological averages of $\mathrm{ET}_{0}$ at hourly (subscript $\mathrm{H}$ ) and daily (subscript D) scale, respectively. These terms are provided by the following equations:

$$
\begin{aligned}
& \left\langle\left.\mathrm{ET}_{0}(h, m)\right|_{\mathrm{H}}\right\rangle=\left.\frac{1}{N_{y}} \frac{1}{N_{m}} \sum_{y=1}^{N_{y}} \sum_{d=1}^{N_{m}} \mathrm{ET}_{0}(h, d, m, y)\right|_{\mathrm{H}}, \\
& \left\langle\left.\mathrm{ET}_{0}(m)\right|_{\mathrm{D}}\right\rangle=\left.\frac{1}{N_{y}} \frac{1}{N_{m}} \sum_{y=1}^{N_{y}} \sum_{d=1}^{N_{m}} \mathrm{ET}_{0}(d, m, y)\right|_{\mathrm{D}},
\end{aligned}
$$

where $N_{m}$ is the number of days in month $m$, and $N_{y}$ is the number of years considered for the climatological 

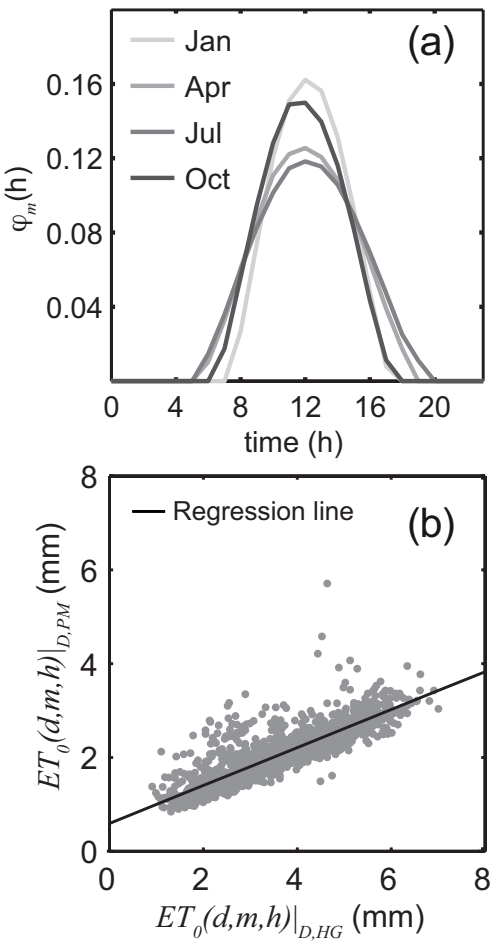

Fig. 7. (a) Dimensionless function $\phi_{m}(h)$ for the months January, April, July and October, and (b) scatterplot between the daily $\mathrm{ET}_{0}$ computed with the PM and HG formula during the spring season (MAM), along with the regression lines.

mean (in our case, $N_{y}=16$ ), while $\left.\mathrm{ET}_{0}(h, d, m, y)\right|_{\mathrm{H}}$ and $\left.\mathrm{ET}_{0}(d, m, y)\right|_{\mathrm{D}}$ are the hourly and daily potential evapotranspiration computed for hour $h$ on day $d$, in month $m$ and year $y$.

The dimensionless functions $\phi_{m}(h)$ can be used to disaggregate $\mathrm{ET}_{0}$ from daily to hourly resolution as

$\left.\mathrm{ET}_{0}(h, d, m, y)\right|_{\mathrm{H}}=\left.\varphi_{m}(h) \cdot \mathrm{ET}_{0}(d, m, y)\right|_{\mathrm{D}}$.

In our application, the functions $\phi_{m}(h)$ were estimated as follows. We used the Penman-Monteith (PM) equation (Allen et al., 1989, 2006) to compute $\left.\mathrm{ET}_{0}(h, d, m, y)\right|_{\mathrm{H}}$ with meteorological data in the period 1995-2010 (Table 3) and values of stomatal resistance and albedo from a study by Montaldo et al. (2008) in Sardinia. From the hourly estimates, we derived $\left.\mathrm{ET}_{0}(d, m, y)\right|_{\mathrm{D}}$ by summing over the $24 \mathrm{~h}$ of each day. The hourly and daily $\mathrm{ET}_{0}$ estimates allowed the application of Eqs. (3) and (4), and, from those, the calculation of the ratios in Eq. (2) to derive the monthly $\phi_{m}(h)$. Examples of $\phi_{m}(h)$ obtained for January, April, July and October are shown in Fig. 7a. As expected, in winter and autumn, $\phi_{m}(h)$ has a more pronounced peak in the central hours of the day due to the shorter daylight period.

As a next step, we derived the term $\left.\operatorname{ET}_{0}(d, m, y)\right|_{\mathrm{D}}$ to be used in Eq. (5). We utilized the Hargreaves (HG) equation (Hargreaves, 1994; Hargreaves and Allen, 2003) to calculate
Table 5. Parameters $p_{0}$ and $p_{1}$ of the linear regression in Eq. (6) between daily $\mathrm{ET}_{0}$ expressed in $\mathrm{mm}$ and computed with the PM and HG formulas for each season (DJF: December, January and February; MAM: March, April and May; JJA: June, July and August; SON: September, October and November). The linear correlation coefficient (CC) and the root mean square error (RMSE) are also reported.

\begin{tabular}{lcccc}
\hline Season & $p_{0}$ & $p_{1}$ & CC & RMSE \\
\hline DJF & 0.409 & 0.367 & 0.608 & 0.165 \\
MAM & 0.593 & 0.404 & 0.835 & 0.322 \\
JJA & 1.486 & 0.269 & 0.538 & 0.361 \\
SON & 0.405 & 0.429 & 0.875 & 0.248 \\
\hline
\end{tabular}

a first estimate of daily $\mathrm{ET}_{0}$ from $T_{\min }$ and $T_{\max }$. Since the functions $\phi_{m}(h)$ were derived through the PM formula, the daily estimates with HG cannot be directly used in Eq. (5). Thus, we investigated the relation between the daily estimates of $\mathrm{ET}_{0}$ obtained with the two methods. The analysis was carried out separately for each season to account for different types of climate and weather conditions. We found that a simple linear relation can be used to link the two estimates:

$\left.\mathrm{ET}_{0}(d, m, y)\right|_{\mathrm{D}, \mathrm{PM}}=p_{0}+\left.p_{1} \cdot \mathrm{ET}_{0}(d, m, y)\right|_{\mathrm{D}, \mathrm{HG}}$,

where the subscripts PM and HG indicate the methods used to compute the daily $\mathrm{ET}_{0}$. The values of $p_{0}$ and $p_{1}$ estimated for each season are reported in Table 5, along with the linear correlation coefficient (CC) and the root mean square error (RMSE) between the daily estimates with PM and HG. Figure $7 \mathrm{~b}$ reports an example for the spring season.

The disaggregation procedure can be used to produce hourly $\mathrm{ET}_{0}$ from $T_{\min }$ and $T_{\max }$ as follows. For a given day $d$ in month $m$ and year $y,\left.\operatorname{ET}_{0}(d, m, y)\right|_{\mathrm{D}}$ in Eq. (5) is estimated by applying in cascade: (i) the HG formula with $T_{\min }$ and $T_{\max }$, and (ii) Eq. (6) with the values of $p_{0}$ and $p_{1}$ dependent on the season. Equation (5) is then used to derive the evapotranspiration at hourly scale $\left.\mathrm{ET}_{0}(h, d, m, y)\right|_{\mathrm{H}}$ for $h=0,1, \ldots, 23$. Table 6 reports the interannual mean RMSE and bias between the hourly $\mathrm{ET}_{0}$ obtained (i) with the disaggregation method starting from $T_{\min }$ and $T_{\max }$, and (ii) with the PM formula using the meteorological data for each season of the period 1995-2010. Despite that the downscaling procedure slightly underestimates the hourly $\mathrm{ET}_{0}$ (negative bias), performances are overall fairly good, as indicated by the low RMSE. 


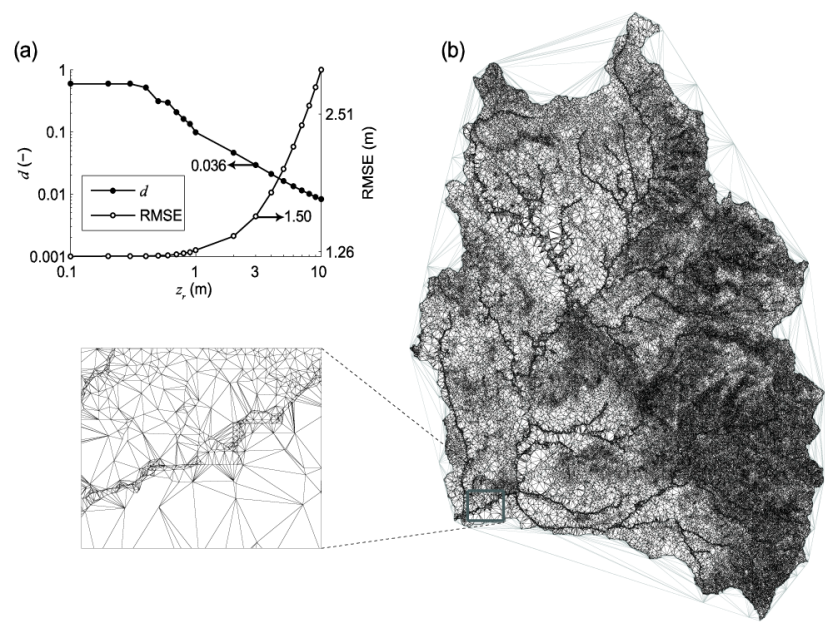

Fig. 8. (a) Relations between vertical accuracy $z_{\mathrm{r}}$ (maximum elevation difference between TIN and DEM) and horizontal point density $d$ and RMSE between DEM and TIN elevations. (b) Voronoi polygons of selected TIN with $z_{\mathrm{r}}=3 \mathrm{~m}$ corresponding to $d=0.036$ and $\mathrm{RMSE}=1.5 \mathrm{~m}$.

\section{Distributed hydrologic simulation with downscaled products}

\subsection{Model setup and meteorological forcing}

The DEM of Fig. 1 was used to create the TIN network for the model. Following the approach of Vivoni et al. (2005), we created and compared several TINs with different resolutions to identify the best compromise between the accuracy of terrain representation and computational effort. A summary of this analysis is presented in Fig. 8a, where the TIN resolution, quantified by the horizontal point density $d$ (ratio between the number of TIN nodes and of DEM pixels), is compared against two metrics characterizing the accuracy, namely the maximum elevation difference $z_{r}$ and the RMSE between TIN and DEM elevations. For our study, we selected a TIN with a total of 171078 nodes, corresponding to $3.6 \%$ of the DEM nodes $(d=0.036)$. This TIN, shown in Fig. 8b, is able to capture adequately the frequency distribution of elevation, slope, curvature and topographic index provided by the original DEM (not shown). In addition, we obtained a soil depth map by combining the DEM and the soil texture information, according to a procedure described on the website of the Distributed Hydrology Soil Vegetation Model (http://www.hydro.washington.edu/Lettenmaier/ Models/DHSVM/tools.shtml).

The precipitation downscaling procedure was applied to create an ensemble of 50 spatiotemporal fields at scale $l \times l \times T_{2}$ for the years 1930-1932, starting from the daily mean rainfall intensities observed in the coarse domain $L \times L$ (Fig. 3). The resulting downscaled precipitation grids were subsequently aggregated in time from $T_{2}=45 \mathrm{~min}$ to $1 \mathrm{~h}$. On non-rainy days, no downscaling was performed and
Table 6. RMSE and bias between (i) the hourly $\mathrm{ET}_{0}$ obtained with the disaggregation method starting from $T_{\min }$ and $T_{\max }$, and (ii) the hourly $\mathrm{ET}_{0}$ estimated with the PM formula using the meteorological data for each season of the years 1995-2010.

\begin{tabular}{lcc}
\hline Season & RMSE $\left(\mathrm{mm} \mathrm{h}^{-1}\right)$ & Bias $\left(\mathrm{mm} \mathrm{h}^{-1}\right)$ \\
\hline DJF & 0.019 & -0.004 \\
MAM & 0.031 & -0.009 \\
JJA & 0.039 & -0.015 \\
SON & 0.029 & -0.011 \\
\hline
\end{tabular}

grids with zero rainfall were created. To test the ability of the disaggregation algorithm further, we compared the observed and simulated series of the daily mean areal precipitation (MAP) in the RMB. The observed series was obtained by applying Thiessen polygons to the observations of the 12 gages of Fig. 1, while the simulated MAP series was derived by aggregating the synthetic grids at daily resolution and computing the spatial basin average. Table 7 reports the RMSE and bias between the observed $\left(\mathrm{MAP}_{0}\right)$ and the ensemble average from the downscaling model $\left(\mathrm{MAP}_{\mathrm{D}}\right)$ for the period 1925-1935. The RMSE computed for rainy days has little interannual variability (average value of $4.38 \mathrm{~mm}$ ), while the bias, again calculated for rainy days, is negative (mean of $-0.89 \mathrm{~mm}$ ), indicating that the downscaling procedure tends to slightly underestimate the observed MAP (less than $10 \%$ ).

The hourly basin-averaged $\mathrm{ET}_{0}$ for the calibration and validation period was generated by (i) applying the disaggregation procedure in each Voronoi polygon of the RMB, and (ii) computing the weighted mean across the basin. The values of $T_{\min }$ and $T_{\max }$ in each Voronoi element were determined by correcting the temperature observed at the station in Cagliari (circle in Fig. 1b) as a function of the element elevation, using an adiabatic lapse rate of $-6.5^{\circ} \mathrm{C} \mathrm{km}^{-1}$.

\subsection{Model calibration and validation}

Different sets of simulations with 50 ensemble members were carried out with the tRIBS model during the calibration period in the year 1930. We utilized a spin-up interval of $2 \mathrm{yr}$ prior to the start of the calibration period following the approach of Vivoni et al. (2005). The model runs were conducted using the parallelized code in the Saguaro supercomputer at Arizona State University. Streamflow observations in the year 1930 were used to adjust the model parameters manually. Following Ivanov et al. (2004b) and results of a sensitivity analysis, the most influential parameters were found to be the saturated hydraulic conductivity at the surface $\left(K_{\mathrm{S}}\right)$ and the conductivity decay parameter $(f)$, used to model the variation of $K_{\mathrm{S}}$ with the soil depth (Cabral et al., 1992). The values of $K_{\mathrm{s}}$ and $f$ were modified within the ranges typical for the corresponding soil texture classes (Fig. 2), while, for the other parameters, we adopted literature values for similar 

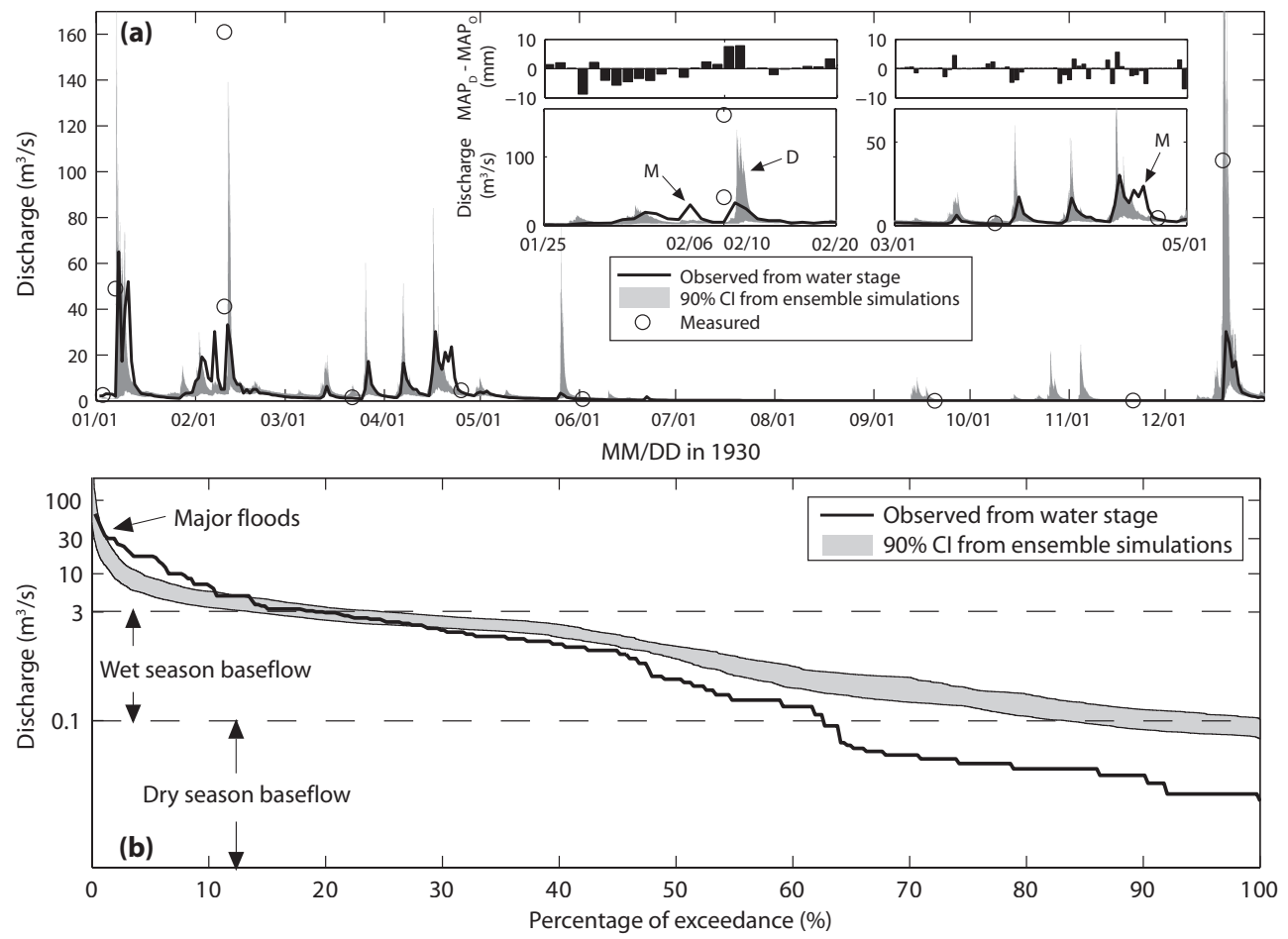

Fig. 9. Result of the tRIBS model calibration (year 1930). (a) Comparison between the observed discharge against the $90 \%$ confidence intervals (CIs) derived from the 50 ensemble simulations of the tRIBS model. In the insets, a zoom on two periods with significant flood events is reported to visualize the comparison better, along with the difference between the daily MAP $_{D}$ and $_{M^{\prime}} P_{O}$ (see text for the definition). The circles represent the discharge values measured by the Italian Hydrologic Survey to update the rating curve. (b) Comparison between the observed flow duration curve and the $90 \%$ confidence intervals derived from the 50 ensemble simulations.

Table 7. RMSE and bias between the daily observed mean areal precipitation $\left(\mathrm{MAP}_{\mathrm{O}}\right)$ and the ensemble average from the downscaling tool and aggregated at daily scale $\left(\mathrm{MAP}_{\mathrm{D}}\right)$ for rainy days. Italic font is used for years selected to calibrate and validate the hydrologic model.

\begin{tabular}{ccc}
\hline Year & RMSE (mm) & Bias (mm) \\
\hline 1925 & 4.34 & -1.06 \\
1926 & 4.28 & -0.78 \\
1927 & 4.18 & -1.49 \\
1928 & 3.95 & -0.60 \\
1929 & 4.19 & -1.31 \\
1930 & 5.63 & -0.64 \\
1931 & 4.27 & -0.76 \\
1932 & 3.15 & -0.74 \\
1933 & 4.86 & -1.35 \\
1934 & 3.97 & -0.29 \\
1935 & 4.48 & -1.03 \\
\hline All & 4.37 & -0.89 \\
\hline
\end{tabular}

soil and vegetation properties (Rawls et al., 1983; Noto et al., 2008; Montaldo et al., 2008; Vivoni et al., 2010). Table 8 presents the parameter values in the main classes.

Figure 9a shows the time series of the observed discharge compared against the $90 \%$ confidence intervals derived from the ensemble streamflow simulations. In the two insets we can better visualize the comparison over two time periods with significant flood events, and appreciate the different resolution between the observations (daily) and model outputs (sub-hourly). For each inset, we also plotted the difference between the downscaled ensemble average $\left(\mathrm{MAP}_{\mathrm{D}}\right)$ and observed $\left(\mathrm{MAP}_{\mathrm{O}}\right)$ mean areal precipitation at the daily scale. Despite the uncertainty in hydrometeorological inputs, the model reproduces, with reasonably accuracy, the shape and timing of the major flood events. In some cases, the mismatch between observed and simulated precipitation inputs leads to underestimation or overestimation of flood peaks. For example, the model is not able to reproduce the peaks labeled as $\mathrm{M}$ (missed), due to a previous period of underestimated precipitation (negative $\mathrm{MAP}_{\mathrm{D}}-\mathrm{MAP}_{\mathrm{O}}$ ). Similarly, the timing of flood peaks can be also affected, as illustrated by the label D (delayed). These discrepancies may not be entirely ascribed to a failure of the proposed procedure. First, the coarse (daily) sampling of stage levels is not sufficient to capture the high frequency of the discharge variability 
Table 8. Parameters of the tRIBS model for the major soil and land cover classes in the RMB.

\begin{tabular}{|c|c|c|c|c|c|c|}
\hline \multirow[b]{2}{*}{$\begin{array}{l}\text { Land cover } \\
\text { properties }\end{array}$} & \multicolumn{6}{|c|}{ Major land cover types } \\
\hline & $\begin{array}{l}\text { Variable } \\
\text { (unit) }\end{array}$ & Agriculture & $\begin{array}{c}\text { Sparse } \\
\text { vegetation }\end{array}$ & Olives & Forests & Pasture \\
\hline Area & $A(\%)$ & 47.64 & 26.08 & 8.07 & 7.09 & 5.43 \\
\hline Vegetation fraction & $v(-)$ & 0.5 & 0.5 & 0.5 & 0.5 & 0.4 \\
\hline Albedo & $a(-)$ & 0.2 & 0.2 & 0.2 & 0.18 & 0.2 \\
\hline Vegetation height & $h(\mathrm{~m})$ & 1.0 & 1.0 & 3.0 & 10.0 & 0.7 \\
\hline Vegetation transmission & $K_{\mathrm{t}}(-)$ & 0.5 & 0.5 & 0.5 & 0.5 & 0.5 \\
\hline \multirow[t]{2}{*}{ Minimum stomatal resistance } & $r_{\min }\left(\mathrm{s} \mathrm{m}^{-1}\right)$ & 100 & 100 & 100 & 100 & 100 \\
\hline & \multicolumn{4}{|c|}{ Major soil types } & & \\
\hline $\begin{array}{l}\text { Soil } \\
\text { properties }\end{array}$ & $\begin{array}{l}\text { Variable } \\
\text { (unit) }\end{array}$ & $\begin{array}{l}\text { Clay loam } \\
\text { - clay }\end{array}$ & $\begin{array}{l}\text { Sandy loam } \\
\text { - loam }\end{array}$ & $\begin{array}{l}\text { Sandy loam } \\
\text { - sandy clay } \\
\text { loam }\end{array}$ & & \\
\hline Area & $A(\%)$ & 36.66 & 31.82 & 19.59 & & \\
\hline Saturated hydraulic conductivity & $K_{\mathrm{S}}\left(\mathrm{mm} \mathrm{h}^{-1}\right)$ & 0.60 & 13.20 & 3.00 & & \\
\hline Conductivity decay & $f\left(\mathrm{~mm}^{-1}\right)$ & 0.00051 & 0.00096 & 0.00096 & & \\
\hline Porosity & $n(-)$ & 0.475 & 0.463 & 0.398 & & \\
\hline Saturated soil moisture & $\theta_{\mathrm{S}}(-)$ & 0.385 & 0.434 & 0.330 & & \\
\hline Residual soil moisture & $\theta_{\mathrm{r}}(-)$ & 0.090 & 0.027 & 0.068 & & \\
\hline Stress soil moisture & $\theta^{*}(-)$ & 0.308 & 0.347 & 0.264 & & \\
\hline Pore size distribution index & $m(-)$ & 0.165 & 0.252 & 0.319 & & \\
\hline
\end{tabular}

Table 9. Nash-Sutcliffe coefficient (NSC) between observed and simulated water volume at daily, weekly, and monthly timescales. The minimum, mean and maximum values across the 50 ensemble members are reported for the calibration and validation periods.

\begin{tabular}{lrr}
\hline Timescale & $\begin{array}{r}\text { Calibration NSC } \\
\text { Min, Mean, Max }\end{array}$ & $\begin{array}{r}\text { Validation NSC } \\
\text { Min, Mean, Max }\end{array}$ \\
\hline Daily & $-3.53,0.07,0.61$ & $-0.99,0.02,0.42$ \\
Weekly & $-5.50,0.46,0.83$ & $-0.72,0.13,0.47$ \\
Monthly & $-0.06,0.55,0.89$ & $0.30,0.25,0.74$ \\
\hline
\end{tabular}

and the magnitude of the flood peaks properly, whereas the sub-hourly resolution of tRIBS outputs allows better representing the system dynamics, as it will be discussed below. Second, since the downscaling tool redistributes in stochastic fashion the daily rainfall volumes from a large domain $(104 \mathrm{~km} \times 104 \mathrm{~km}$, see Fig. 3) to smaller areas and times, it may be possible that, on some days, the multifractal model fails to capture the exact spatial localization of the storms. As a consequence, cases where $\mathrm{MAP}_{\mathrm{D}}$ and $\mathrm{MAP}_{\mathrm{O}}$ differ should be somehow expected, as they are part of the uncertainty associated with the disaggregation approach.

The circles in Fig. 9a are the streamflow measurements made by the Italian Hydrologic Survey during campaigns aimed at updating the rating curve. Some of these observations were collected during three major flood events. One can note how the model is able to capture fairly well the magnitude of the high values observed between two daily discharge readings. This is an important and promising result that builds confidence on the model utility for analyses of flood frequency under climate change. Table 9 reports the Nash-Sutcliffe coefficient (NSC) (Nash and Sutcliffe, 1970) computed for the water volume derived from the observed streamflow and the ensemble streamflow simulations. Specifically, the minimum, mean and maximum values of the 50 ensemble members are reported for different aggregation times (daily, weekly and monthly). Linear variability between discharge observations is assumed to calculate the volume. Clearly, the lowest values of NSC (poor performances) are obtained at daily resolution, because at this scale the direct correspondence between observation and simulations is more affected by the different sampling time step and by mismatching in the disaggregated forcing. When larger timescales are considered, NSC increases and reaches a mean value of 0.55 at monthly resolution. In terms of total runoff volume, the ensemble mean is $170 \mathrm{~mm}$ (standard deviation, STD, of $70 \mathrm{~mm}$ across the 50 members) and the observation is $183 \mathrm{~mm}$. This underestimation $(\sim 10 \%)$ can be explained by the lower simulated MAP (mean and STD of 848 and $118 \mathrm{~mm})$ as compared to the observation $(902 \mathrm{~mm})$. In both the observed streamflow and the ensemble mean, the runoff coefficient was found to be $\sim 0.20$ for this period.

To illustrate the model performance further, Fig. $9 \mathrm{~b}$ shows the comparison between the observed flood duration curve 

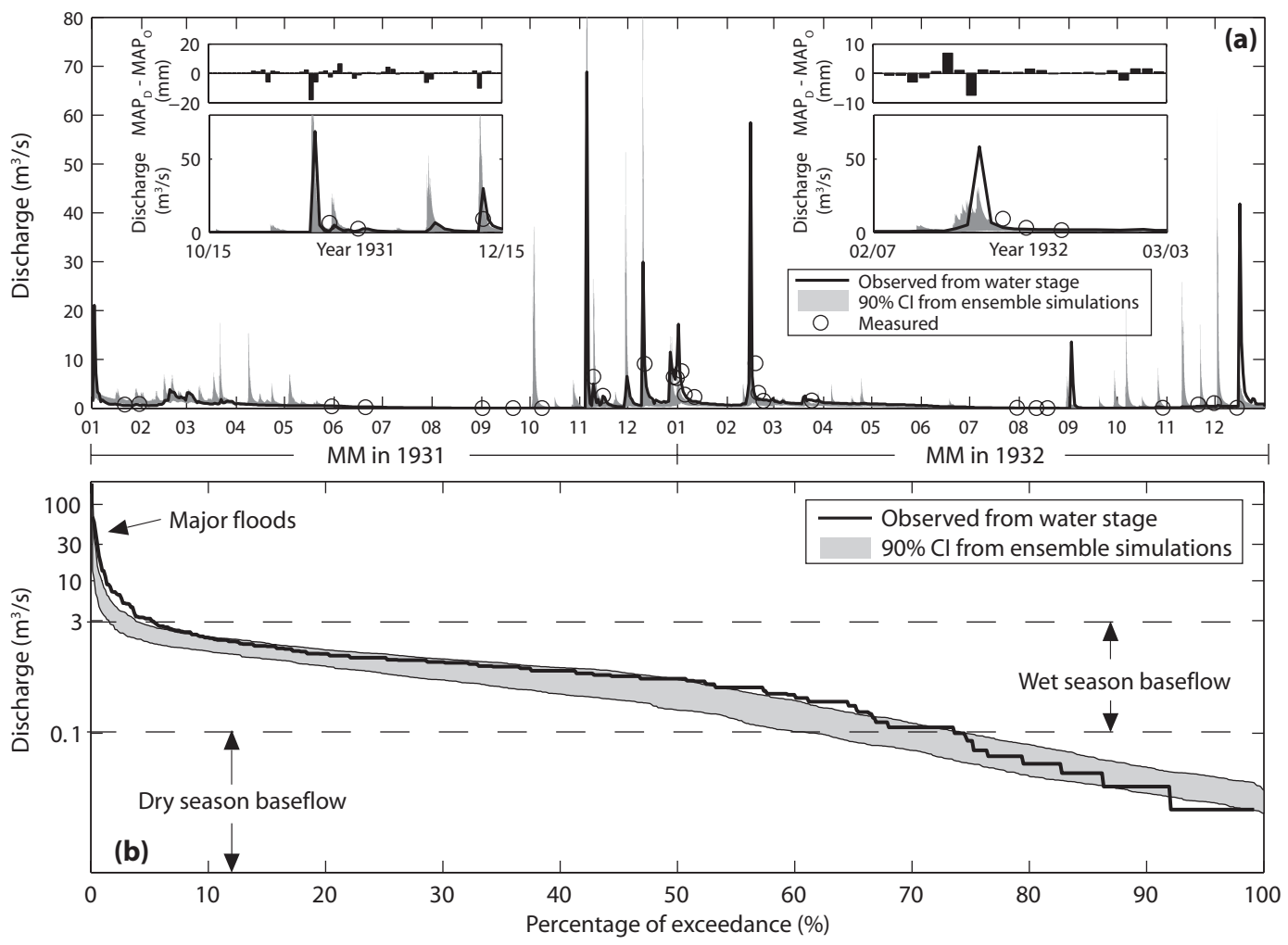

Fig. 10. Result of the tRIBS model validation (years 1931-1932). See Fig. 9 for a description of the figure content.

(FDC) and the $90 \%$ confidence intervals from the ensemble simulations. The shape of the observed FDC is well reproduced within the range of wet season baseflow and for the major flood events. The model underestimates the streamflow values corresponding to the percentage of exceedance of 2 to $10 \%$, due to a tendency to simulate steeper recession limbs. The shapes of simulated and observed FDCs diverge in the interval of dry season baseflow. However, in this range of discharge values, the absolute error between the observations and simulations is very low, and the observed data are quite uncertain, as they are affected by releases from urban and irrigation activities.

Results for the validation period (years 1931 and 1932) are shown in Fig. 10. Note the good performances in reproducing the discharge time series (Fig. 10a) over year 1931 and most of 1932. In the period from October to December 1932, the model simulates a number of peaks that were not observed, while sometimes underestimates the discharge, due to the same reasons discussed for the calibration period. These peaks lower the NSC values at the different aggregation times, as reported in Table 9. As in the calibration period, the total simulated runoff volume (mean of $103 \mathrm{~mm}$ and STD of $17 \mathrm{~mm}$ ) is lower than the observation $(147 \mathrm{~mm})$, due to lower precipitation simulated by the downscaling tool (mean of $993 \mathrm{~mm}$ and STD of $96 \mathrm{~mm}$ ) as compared to the observed total $(1025 \mathrm{~mm})$. The simulated runoff coefficient throughout the two years is on average 0.10 in the simulations, slightly smaller than the observed value of 0.14 . Despite the discrepancies present in the time series and the metrics, Fig. 9b reveals an excellent agreement between the shapes of observed and simulated FDCs, even in the range of the dry season baseflow. Overall, these results suggest that the combined use of the downscaling algorithms and the tRIBS model allows reproducing with reasonable accuracy the hydrologic response of the RMB within the $3 \mathrm{yr}$ selected for calibration and validation. This holds promise for a subsequent application of these simulation tools to evaluate the local impacts of future climate change scenarios, assuming that their calibration is stationary in time.

\section{Summary and conclusions}

We applied a physically based distributed hydrologic model in the Rio Mannu basin, a medium-sized watershed (area of $472.5 \mathrm{~km}^{2}$ ) on the Mediterranean island of Sardinia, Italy. In the RMB, precipitation, streamflow and meteorological data were collected in different historical periods and at diverse temporal resolutions. We showed how this sparse hydrometeorological data set could be used to calibrate two downscaling tools that are able to create high-resolution (hourly) precipitation forcing from daily observations and estimates 
of the hourly potential evapotranspiration for use in the distributed hydrologic model application.

Despite the presence of several sources of uncertainty in the observations and model parameterization, the use of the downscaled forcing led to good calibration and validation performances for the tRIBS model over the years from 1930 to 1932 with available daily discharge observations. To our knowledge, this is the first study whereby a distributed hydrologic model is applied on the island of Sardinia. Different from most applications based on daily forcing, the methodology proposed here allows conducting hydrologic simulations at high time and space resolutions, thus capturing with higher detail the complex interactions between surface and subsurface processes occurring in Mediterranean watersheds. This methodology will be utilized in a subsequent study to disaggregate the outputs of different RCMs and simulate the hydrologic response of the RMB under different climate change scenarios, thus quantifying their local impacts on water resources and the frequency of hydrologic extremes.

Acknowledgements. The authors thank two anonymous reviewers for their comments that helped to improve the quality of the manuscript. This study has been developed within the project CLIMB (Climate Induced Changes on the Hydrology of Mediterranean Basins: Reducing Uncertainty and Quantifying Risk through an Integrated Monitoring and Modeling System, http://www.climb-fp7.eu), funded by the European Commission's 7 th Framework Programme. The authors also thank financial support from the Sardinian Region L.R. 7/2007, funding call 2008.

Edited by: A. Gelfan

\section{References}

Abbaspour, K. C., Faramarzi, M., Ghasemi, S. S., and Yang, H.: Assessing the impact of climate change on water resources in Iran, Water Resour. Res., 45, W10434, doi:10.1029/2008WR007615, 2009.

Allen, R. G., Jensen, M. E., Wright, J. L., and Burman, R.D.: Operational estimates of reference evapotranspiration, Agron. J., 81, 650-662, 1989.

Allen, R. G., Pruitt, W. O., Wright, J. L., Howell, T. A., Ventura, F., Snyder, R., Itenfisu, D., Steduto, P., Berengena, J., Yrisarry, J. B., Smith, M., Pereira, L. S., Raes, D., Perrier, A., Alves I., Walter, I., and Elliott, R.: A recommendation on standardized surface resistance for hourly calculation of reference $\mathrm{ET}_{0}$ by the FAO56 Penman-Monteith method, Agr. Water Manage., 81, 122, doi:10.1016/j.agwat.2005.03.007, 2006.

Aru, A., Baldaccini, P., and Vacca, A.: Carta dei suoli della Sardegna 1:250,000. Regione Autonoma della Sardegna, Assessorato Programmazione, Bilancio ed Assetto del Territorio, 1992.

Badas, M. G., Deidda, R., and Piga, E.: Modulation of homogeneous space-time rainfall cascades to account for orographic influences, Nat. Hazards Earth Syst. Sci., 6, 427-437, doi:10.5194/nhess-6-427-2006, 2006.
Beven, K.: Runoff generation in semi-arid areas, in: Dryland Rivers, edited by: Bull, L. J. and Kirkby, M. J., J. Wiley \& Sons, 57-105, 2002.

Cabral, M. C., Garrote, L., Bras, R. L., and Entekhabi, D.: A kinematic model of infiltration and runoff generation in layered and sloped soils, Adv. Water Resour., 15, 311-324, 1992.

Camporese, M., Paniconi, C., Putti, M., and Orlandini, S.: Surfacesubsurface flow modeling with path-based runoff routing, boundary condition-based coupling, and assimilation of multisource observation data, Water Resour. Res., 46, W02512, doi:10.1029/2008WR007536, 2010.

Cayan, D. R., Dasa, T., Piercea, D. W., Barnetta, T. P., Tyreea, M., and Gershunova, A.: Future dryness in the southwest US and the hydrology of the early 21 st century drought, P. Natl. Acad. Sci. USA, 107, 21271-21276. doi:10.1073/pnas.0912391107, 2010.

Chessa, P. A., Cesari, D., and Delitala, A. M. S.: Mesoscale precipitation and temperature regimes in Sardinia (Italy) and their related synoptic circulation, Theor. Appl. Climatol., 63, 195-221, 1999.

Chessa, P. A., Ficca, G., Marrocu, M., and Buizza, R.: Application of a limited-area short-range ensemble forecast system to a case of heavy rainfall in the Mediterranean region, Weather Forecast., 19, 566-581, 2004.

Deidda, R.: Rainfall downscaling in a space-time multifractal framework, Water Resour. Res., 36, 1779-1784, 2000.

Deidda, R., Benzi, R., and Siccardi, F.: Multifractal modeling of anomalous scaling laws in rainfall, Water Resour. Res., 35, 18531867, 1999.

Deidda, R., Badas, M. G., and Piga, E.: Space-time scaling in highintensity Tropical Ocean Global Atmosphere Coupled OceanAtmosphere Response Experiment TOGA-COARE storms, Water Resour. Res., 40, W02506, doi:10.1029/2003WR002574, 2004.

Deidda, R., Badas, M. G., and Piga, E.: Space-time Multifractality of Remotely Sensed Rainfall Fields, J. Hydrol., 322, 2-13, 2006.

Delrieu, G., Nicol, J., Yates, E., Kirstetter, P.-E., Creutin, J.-D., Anquetin, S., Obled, C., and Saulnier, G.-M.: The catastrophic flash-flood event of 8-9 September 2002 in the Gard region, France: a first case study for the Cévennes-Vivarais Mediterranean hydrometeorological observatory, J. Hydrometeorol., 6, 34-52, 2005.

Forman, B. A., Vivoni, E. R., and Margulis, S. A.: Evaluation of ensemble-based distributed hydrologic model response with disaggregated precipitation products, Water Resour. Res., 44, 1-18, doi:10.1029/2008WR006827, 2008.

Frei, C., Schöll, R., Fukutome, S., Schmidli, J., and Vidale, P. L.: Future change of precipitation extremes in Europe: intercomparison of scenarios from regional climate models, J. Geophys. Res., 111, D06105, doi:10.1029/2005JD005965, 2006.

Gallart, F., Llorens, P., Latron, J., and Regüés, D.: Hydrological processes and their seasonal controls in a small Mediterranean mountain catchment in the Pyrenees, Hydrol. Earth Syst. Sci., 6, 527-537, doi:10.5194/hess-6-527-2002, 2002.

Gebremichael, M., Over, T. M., and Krajewski, W. F.: Comparison of the scaling properties of rainfall derived from space- and surface-based radars, J. Hydrometeor., 7, 1277-1294, 2006.

Giorgi, F.: Climate change hot-spots, Geophys. Res. Lett., 33, L08707, doi:10.1029/2006GL025734, 2006. 
Hargreaves, G. H.: Defining and using reference evapotranspiration, J. Irrig. Drain. E.-ASCE, 120, 1132-1139, 1994.

Hargreaves, G. H. and Allen, R. G.: History and evaluation of Hargreaves Evapotraspiration equation, J. Irrig. Drain. E.-ASCE, 129, 53-63, 2003.

IPCC (Intergovernmental Panel on Climate Change): Climate Change 2007: impacts, adaptation and vulnerability, Contribution of Working Group II to the Fourth Assessment Report of the Intergovernmental Panel on Climate Change, Cambridge University Press, Cambridge, UK, 976, 2007.

IPCC (Intergovernmental Panel on Climate Change): Climate Change and Water, Technical Paper of the Intergovernmental Panel on Climate Change, IPCC Secretariat, Geneva, 210, 2008.

Ivanov, V. Y., Vivoni, E. R., Bras, R. L., and Entekhabi, D.: Catchment hydrologic response with a fully-distributed triangulated irregular network model, Water Resour. Res., 40, 1-23, doi:10.1029/2004WR003218, 2004a.

Ivanov, V. Y., Vivoni, E. R., Bras, R. L., and Entekhabi, D.: Preserving high-resolution surface and rainfall data in operational-scale basin hydrology: A fully-distributed physically-based approach, J. Hydrol., 298, 80-111, doi:10.1016/j.jhydrol.2004.03.041, 2004b.

Langousis, A., Veneziano, D., Furcolo, P., and Lepore, C.: Multifractal rainfall extremes: Theoretical analysis and practical estimation, Chaos Soliton. Fract., 39, 1182-1194, doi:10.1016/j.chaos.2007.06.004, 2009

Langousis, A., Carsteanu, A. A., and Deidda, R.: A simple approximation to multifractal rainfall maxima using a generalized extreme value distribution model, Stoch. Environ. Res. Risk Assess., 27, 1525-1531, doi:10.1007/s00477-013-0687-0, 2013.

Liuzzo, L., Noto, L. V., Vivoni, E. R., and La Loggia, G.: Basin-scale water resources assessment in Oklahoma under synthetic climate change scenarios using a fully distributed hydrological model, J. Hydrol. Eng., 15, 107-122, doi:10.1061/(ASCE)HE.1943-5584.0000166, 2010.

Ludwig, R., Soddu, A., Duttmann, R., Baghdadi, N., Benabdallah, S., Deidda, R., Marrocu, M., Strunz, G., Wendland, F., Engin, G., Paniconi, C., Prettenthaler, F., Lajeunesse, I., Afifi, S., Cassiani, G., Bellin, A., Mabrouk, B., Bach, H., and Ammerl, T.: Climateinduced changes on the hydrology of Mediterranean basins - A research concept to reduce uncertainty and quantify risk, Fresen. Environ. Bull., 19, 2379-2384, 2010.

Mahfouf, J. F. and Noilhan, J.: Comparative study of various formulations from bare soil using in situ data, J. Appl. Meteorol., 30, 1354-1365, 1991.

Mascaro, G., Vivoni, E. R., and Deidda, R.: Implications of ensemble quantitative precipitation forecast errors on distributed streamflow forecasting, J. Hydrometeorol., 11, 69-86, doi:10.1175/2009JHM1144.1, 2010.

Mascaro, G., Deidda, R., and Hellies, M.: On the nature of rainfall intermittency as revealed by different metrics and sampling approaches, Hydrol, Earth Syst. Sci., 17, 355-369, doi:10.5194/hess-17-355-2013, 2013.

Menabde, M., Harris, D., Seed, A,. Austin, G., and Stow, D.: Multiscaling properties of rainfall and bounded random cascades, Wat. Resour. Res., 33, 2823-2830, 1997.

Montaldo, N., Albertson, J. D., and Mancini, M.: Vegetation dynamics and soil water balance in a water-limited Mediterranean ecosystem on Sardinia, Italy, Hydrol. Earth Syst. Sci., 12, 1257 1271, doi:10.5194/hess-12-1257-2008, 2008.

Monteith, J. L.: Evaporation and environment, Sym. Soc. Exp. Biol., 19, 205-234, 1965.

Montenegro, S. and Ragab, R.,: Impact of possible climate and land use changes in the semi arid regions: a case study from North Eastern Brazil, J. Hydrol., 434-435, 55-68, doi:10.1016/j.jhydrol.2012.02.036, 2012.

Moussa, R., Chahinian, N., and Bocquillon, C.: Distributed hydrological modeling of a Mediterranean mountainous catchment model construction and multi-site validation. J. Hydrol., 337, 3551, doi:10.1016/j.jhydrol.2007.01.028, 2007.

Nash, J. E. and Sutcliffe, J. V.: River flow forecasting through conceptual models part I - A discussion of principles, J. Hydrol., 10, 282-290, 1970.

Nikolopoulus, E. I., Anagnostou, E. N., Borga, M., Vivoni, E. R., and Papadopoulus, A.: Sensitivity of a mountain basin flash flood to initial wetness condition and rainfall variability, J. Hydrol., 402, 165-178, doi:10.1016/j.jhydrol.2010.12.020, 2011.

Noto, L. V., Ivanov, V. Y., Bras, R. L., and Vivoni, E. R.: Effects of initialization on response of a fully-distributed hydrologic model, J. Hydrol., 352, 107-125, doi:10.1016/j.jhydrol.2007.12.031, 2008.

Olesen, J. E. and Bindi, M.: Consequences of climate change for European agricultural productivity, land use and policy, Eur. J. Agron., 16, 239-262, 2002.

Over, T. M. and Gupta, V. K.: A space-time theory of mesoscale rainfall using random cascades, J. Geophys. Res., 101, 2631926331, 1996.

Penman, H. L.: Natural evaporation from open water, bare soil and grass, P. R. Soc. London, Ser.-A, 193, 120-145, 1948.

Perica, S. and Foufoula-Georgiou, E.: Model for multiscale disaggregation of spatial rainfall based on coupling meteorological and scaling descriptions, J. Geophys. Res., 101, 26347-26361, 1996.

Piñol, J., Beven, K., and Freer, J.: Modelling the hydrological response of Mediterranean catchments, Prades, Catalonia. The use of distributed models as aids to hypothesis formulation, Hydrol. Process., 11, 1287-1306, 1997.

Pulina, M. A.: L'Evapotraspirazione potenziale in Sardegna in funzione dello studio del regime idrico dei suoli. Studi sassaresi: organo ufficiale della Società sassarese di Scienze mediche e naturali. Sez. 3: Annali della Facoltà di Agraria dell'Università di Sassari, Vol. 32, 96-109, ISSN 0562-2662, 1986.

Rawls, W. J., Brakensiek, D. L., and Saxton, K. E.: Estimation of soil properties, T. ASAE, 1316-1328, 1982.

Robles-Morua, A., Vivoni, E. R., and Mayer, A. S.: Distributed hydrologic modeling in Northwest Mexico reveals the links between runoff mechanisms and evapotranspiration, J. Hydrometeor., 13, 785-807, doi:10.1175/JHM-D-11-0112.1, 2012.

Schertzer, D. and Lovejoy, S.: Physical modeling and analysis of rain and clouds by anisotropic scaling of multiplicative processes, J. Geophys. Res., 92, 9693-9714, 1987.

Schröter, D., Cramer, W., Leemans, R., Prentice, I. C., Araújo, M. B., Arnell, N. W., Bondeau, A., Bugmann, H., Carter, T. R., Gracia, C. A., de la Vega-Leinert, A. C., Erhard, M., Ewert, F., Glendining, M., House, J. I., Kankaanpää, S., Klein, R. J. T., Lavorel, S., Lindner, M., Metzger, M. J., Meyer, J., Mitchell, T. D., Reginster, I., Rounsevell, M., Sabaté, S., Sitch, S., Smith, B., Smith, J., 
Smith, P., Sykes, M. T., Thonicke, K., Thuiller, W., Tuck, G., Zaehle, S., and Zierl, B.: Ecosystem service supply and vulnerability to global change in Europe, Science, 310, 1333-1337, 2005.

Silvestro, F., Gabellani, S., Giannoni, F., Parodi, A., Rebora, N., Rudari, R., and Siccardi, F.: A hydrological analysis of the 4 November 2011 event in Genoa, Nat. Hazards Earth Syst. Sci., 12, 2743-2752, doi:10.5194/nhess-12-2743-2012, 2012.

Sulis, M., Paniconi, C., Rivard, C., Harvey, R., and Chaumont, D.: Assessment of climate change impacts at the catchment scale with a detailed hydrological model of surface-subsurface interactions and comparison with a land surface model, Water Resour. Res., 47, W01513, doi:10.1029/2010WR009167, 2011.

VanderKwaak, J. E. and Loague, K.: Hydrologic-response simulations for the R-5 catchment with a comprehensive physics-based model, Water Resour. Res., 37, 999-1013, 2001.

Veneziano, D. and and Langousis, A.: The areal reduction factor a multifractal analysis, Wat. Resour. Res., 41, W07008, doi:10.1029/2004WR003765, 2005.

Veneziano, D. and Langousis, A.: Scaling and fractals in hydrology, in: Advances in Data-based Approaches for Hydrologic Modeling and Forecasting, edited by: B. Sivakumar and R. Berndtsson, World Scientific, 145 pp., 2010.

Veneziano, D., Furcolo, P., and Iacobellis, V.: Imperfect scaling of time and space-time rainfall, J. Hydrol., 322, 105-119, 2006.

Vivoni, E. R., Ivanov, V. Y., Bras, R. L., and Entekhabi, D.: Generation of triangulated irregular networks based on hydrological similarity, J. Hydrol. Eng., 9, 288-302, doi:10.1061/(ASCE)1084-0699(2004)9:4(288), 2004.

Vivoni, E. R., Ivanov, V. Y., Bras, R. L., and Entekhabi, D.: On the effects of triangulated terrain resolution on distributed hydrologic model response, Hydrol. Process., 19, 2101-2122, doi:10.1002/hyp.5671, 2005.
Vivoni, E. R., Entekhabi, D., Bras, R. L., Ivanov, V. Y., Van Horne, M. P., Grassotti, C., and Hoffman, R. N.: Extending the predictability of hydrometeorological flood events using radar rainfall nowcasting, J. Hydrometeorol., 7, 660-677, 2006.

Vivoni, E. R., Entekhabi, D., Bras, R. L., and Ivanov, V. Y.: Controls on runoff generation and scale-dependence in a distributed hydrologic model, Hydrol. Earth Syst. Sci., 11, 1683-1701, doi:10.5194/hess-11-1683-2007, 2007.

Vivoni, E. R., Tai, K., and Gochis, D. J.: Effects of initial soil moisture on rainfall generation and subsequent hydrologic response during the North American monsoon, J. Hydrometeorol., 10, 644-664, doi:10.1175/2008JHM1069.1, 2009.

Vivoni, E. R., Rodriguez, J. C., and Watts, C. J.: On the spatiotemporal variability of soil moisture and evapotranspiration in a mountainous basin within the North American monsoon region, Water Resour. Res., 46, W02509, doi:10.1029/2009WR008240, 2010.

Vivoni, E. R., Mascaro, G., Mniszewski, S., Fasel, P., Springer, E. P., Ivanov, V. Y., and Bras, R. L.: Real-world hydrologic assessment of a fully-distributed hydrological model in a parallel computing environment, J. Hydrol., 409, 483-496, doi:10.1016/j.jhydrol.2011.08.053, 2011.

Wood, A. W., Leung, L. R., Sridhar, V., and Lettenmaier, D. P.: Hydrologic implications of dynamical and statistical approaches to downscaling climate model outputs, Clim. Change, 62, 189-216, 2004. 